\title{
Madame Grandet: la sumisión conyugal en Eugénie Grandet de Balzac
}

\author{
Emilie M. Daniel Cersosimo \\ Escuela de Lenguas Modernas \\ Universidad de Costa Rica
}

\section{Resumen}

En este artículo se analiza la condición de servilismo en el matrimonio del personaje de Madame Grandet en la novela Eugénie Grandet, de Honoré de Balzac, desde el punto de vista del feminismo y la teoría de género.

Palabras claves: mujer, literatura francesa, feminismo, género

\section{Abstract}

This article analyses the condition of marital servilism of the character of Madame Grandet of Balzac's novel Eugénie Grandet according to the point of view of the feminism and the gender theory.

Key words: woman, French literature, feminism, gender 
a. Las teorías feministas según la perspectiva de género

L

a perspectiva de género surge en la segunda mitad del siglo $\mathrm{XX}$ en el ámbito de las ciencias sociales, particularmente de la misma teoría de género. Responde a la necesidad de abordar de manera integral, histórica y dialéctica las implicaciones económicas, políticas, psicológicas y culturales en la vida social de los géneros, es decir, en la organización patriarcal de la sociedad. Enfoca a los hombres y a las mujeres como sujetos históricos construidos socialmente, ubicándolos en su circunstancia histórica.

Las teorías feministas coinciden en el supuesto de que la constitución de diferencias de género es un proceso histórico y social, no un hecho natural. Aún más, es necesario cuestionar la oposición misma entre sexo y género. El sexo se define como las características biológicas del ser hombre o ser mujer que están determinadas antes del nacimiento de la persona y son básicamente inmodificables. Este término proviene del latín sexus que significa ser femenino o ser masculino. Se refiere además a las diferencias biológicas entre hombres y mujeres; no debe confundirse con género, que se relaciona con las diferencias socioculturales.

Así, desde el género se analizan las formas en que se maneja ser hombre o ser mujer a partir de los papeles que les impone la cultura a las personas, es decir, con las creencias que tiene la gente de que alguien por ser hombre o por ser mujer debe comportarse de una u otra manera preestablecida y modelada. El género es el conjunto de características que determinan que ser hombre o mujer no depende de factores biológicos (haber nacido con rasgos genitales y reproductores masculinos o femeninos), sino de la cultura y como esta define lo masculino y lo femenino. Es una construcción cultural que puede cambiar a través del tiempo; el sexo es generalmente inmutable.

La palabra género proviene del latín genus, tipo, especie, clase de individuo o cosa. Demarca las diferencias socioculturales que existen entre mujeres y varones en determinados períodos históricos y culturales, impuestos por los sistemas de organización y, por lo tanto, modificables. Existen dos tipos de género, el femenino y el masculino. Además, el género se integra históricamente por el conjunto de cualidades biológicas, físicas, económicas, políticas y culturales asignadas a los individuos según su sexo. El género es un concepto integral, dinámico e histórico. Es el conjunto de normas aceptadas históricamente de ser mujer u hombre en cada época, en cada sociedad y en cada cultura.

En el personaje de Madame Grandet, se pueden encontrar características que le han sido asignadas por su género femenino y por la tradición de sumisión que pesaban sobre la mujer del siglo XIX desde la antigüedad en Francia. En Eugénie Grandet, la imagen que se da de la madre es la de una mujer que ha sido reducida al estado de servilismo ${ }^{1}$ y sumisión. Además, se dice que es una ilota, una esclava, sierva ${ }^{2}$ y una persona obediente, excluida de las ventajas de que gozan los demás. Ciertamente, Madame Grandet carece de los privilegios que debería disfrutar por su posición económica. Su esposo, Monsieur Grandet es dueño de tierras y tiene una gran 
fortuna acumulada. Se dice que este se casó con ella por ser hija de un rico mercader de tablas ${ }^{3}$. Sin embargo, es un gran avaro y mantiene en su casa un régimen estricto acerca de los gastos de la comida y del fuego (143). Además, cuando se encontraba en una situación de negocios, ponía como pretexto que no podía decidir nada sin antes consultarle a su esposa, lo cual era falso, y de esta forma escapaba. El narrador confirma que es el mismo marido quien se había encargado del estado de servilismo de Madame Grandet: "Sa femme qu'il avait réduite à un ilotisme complet... était son paravent le plus commode" (70). Se puede constatar que la madre es una mujer sumisa por causa de la dominación de su esposo.

La perspectiva de género se construye a partir de las teorías feministas porque estas se han desarrollado desde la opresión genérica patriarcal y machista sobre las mujeres. Madame Grandet es una mujer oprimida por su esposo, quien se consideraba superior a ella, porque era una provinciana y tratada como una mujer minimizada y por lo cual se encontraba en un estado permanente de inferioridad:

"[...] La femme de province est donc dans un état constant de flagrante infériorité" [...] Cette pensée rongeuse opprime la femme de province. [...] Inférieure comme femme, elle est inférieure par son mari”. (288)

\section{b. El patriarcado}

Dentro de este, la desigualdad se concreta en las posibilidades culturales, políticas y sociales de la vida, puesto que los hombres por el solo hecho de serlo tienen el poder del dominio. En cambio, las mujeres, también por el solo hecho de serlo, están sujetas a la opresión genérica. El hombre es entonces portador del dominio: detenta el poder en la relación de género.

Además, el patriarcado se extiende al poder de los padres. Se crea un sistema familiar y social, e ideológico y político con el que la sociedad patriarcal, a través de la fuerza, la presión directa, los rituales, la tradición, la ley, el lenguaje, las costumbres, la etiqueta, la educación y la división del trabajo, determina el papel que la mujer debe interpretar con el fin de someterse en toda circunstancia al varón.

En Eugénie Grandet, existe la dominación total de Monsieur Grandet sobre su esposa y su hija. Ambas le temen y mantienen una conducta pasiva. En la siguiente cita se ve cómo las dos mujeres son comparadas con dos ratones asustados que se esconden rápidamente en sus madrigueras como dos animales que se sienten amenazados y temen por su vida, pues el hombre de la casa es quien manda: "En entendant ses mots, la mère et la fille rentrèrent dans leurs chambres et se fourrèrent dans leurs lits avec la célérité de souris effrayés qui rentrent dans leurs trous" (156).

La madre, al igual que su hija y $\mathrm{Na-}$ non, la sirvienta de la familia Grandet, tienen temor de Monsieur Grandet, a quien creen capaz de pegarles si este llega a enterarse de los gastos incurridos por la llegada de Charles: "Si ton père s'aperçoit de quelque chose, dit madame Grandet, il est capable de nous battre"(137).

El patriarcado es una forma de estructurar la realidad en términos binarios de bueno o malo, redención o culpa, autoridad u obediencia, premio o castigo, poder o impotencia, amo o esclavo. El padre nombraba, poseía, controlaba, 
ordenaba, perdonaba y daba, considerándose a sí mismo el indicado para tomar las decisiones por los demás.

En una ocasión, Madame Grandet deseaba vestir de luto debido a la muerte de su cuñado, el padre de Charles y a su vez hermano de Monsieur Grandet. Sin embargo, este se lo prohíbe; pone como pretexto que el deseo de su mujer era gastar dinero y le dice que el luto se lleva en el corazón y no en la vestimenta. Madame Grandet se sometió a las disposiciones de su marido y le obedeció:

- Mon bon ami, dit madame Grandet, lorsque la nappe fut ôtée, il faut que nous prenions le deuil.

- En vérité, madame Grandet, vous ne savez quoi vous inventer pour dépenser de l'argent. Le deuil est dans le cœur et non dans les habits. (154)

Cabe mencionar la importancia de la utilización de adjetivos y verbos, pues videncian la sumisión que vivía Madame Grandet bajo el dominio de su marido. Ella es constantemente llamada por el narrador pobre mujer. Esta calificación aparece repetida nueve veces a lo largo de la novela. También se utiliza el mismo adjetivo con otras palabras como pobre vieja, pobre madre y pobre ilota. Se pueden agregar otros términos como aire tímido y total servidumbre que verifican la opresión genérica de este personaje femenino: "un air timide" (84), "entière servitude" (84) / "la pauvre femme" (84, 85, 156, 157, 164, 215, 220, 238) / "pauvre vieille" (143) / "la pauvre ilote" (144) / "pauvre mère" (213,239).

\section{c. El sexismo}

De acuerdo con los antecedentes históricos, el tipo de familia modelo, en la sociedad francesa del siglo XIX, se basa en el sistema patriarcal, en donde el padre es el jefe del hogar. Tal concepción se encuentra, frecuentemente, asociada a regímenes estatales dictatoriales en donde gran parte de la sociedad vive inmersa en un esquema de obediencia y sumisión a la autoridad. En Eugénie Grandet Monsieur Grandet, es el amo y señor de su casa y hace que su esposa le sea obediente y sumisa.

Como ya se ha mencionado, el código napoleónico impuso el control del marido sobre la esposa durante el décimo noveno siglo, lo que fomentó el sexismo; se oprimía a las mujeres por causa de su diferenciación sexual:

El Código Civil napoleónico (1804), en el que se recogieron los principales avances sociales de la revolución, negó a las mujeres los derechos civiles reconocidos para los hombres durante el período revolucionario (igualdad jurídica, derecho de propiedad...) e impulsó las leyes discriminatorias, según las cuales el hogar era definido como el ámbito exclusivo de la actuación femenina.

El sexismo se puede expresar de distintas formas y una de ellas muy extendida es el machismo, desde el cual la mujer es inferior al hombre. También, el machismo estructura la opresión de género para marginar, segregar, maltratar, discriminar y cosificar a las mujeres. Madame Grandet y su hija son constantemente víctimas de esta forma de opresión. En el siglo XIX y en épocas antiguas, se acostumbraba que los padres escogieran el novio o 
esposo de las hijas. Madame Grandet habla de los posibles cónyuges para su descendiente. Eugénie es tratada aquí como un objeto que sus padres pueden negociar y su madre acepta pasivamente esta situación. Además, se dice que Madame Grandet expresa en su mirada la condición en la que vive, que el narrador califica como total servidumbre conyugal bajo la cual gemía $^{4}$ la pobre mujer. Se puede ver que existe también otra expresión del paternalismo, que ubica a las mujeres como seres incapaces de inteligencia, dependientes, sumisos, débiles y obedientes entre otras características:

Je ne vois point de partis pour elle à Saumur répondit Mme Grandet en regardant son mari d'un air timide qui, vu son âge annonçait l'entière servitude conjugale sous laquelle gémissait la pauvre femme. (84)

La madre ve a su esposo de forma tímida y sufre su subordinación en silencio.

En el sexismo, existen estereotipos sobre la personalidad masculina y femenina. En cuanto a esta, se encuentra que la mujer debe ser agradable, dedicada a la asistencia y al consuelo, como se ha señalado, abnegada y compasiva entre otras particularidades. Evidentemente, Madame Grandet responde a esos estereotipos. Es buena esposa, quiere a su marido a pesar de vivir sometida a sus reglas, y es generosa, ya que intercede por su hija y le dice a su esposo que ha sido buena esposa y que lo quiere (224).

\section{d. Función asignada por razón de género}

Los comportamientos, tareas y responsabilidades de mujeres y varones están socialmente determinados, lo que define cómo las personas tendrían que pensar, actuar y sentir según sus respectivos sexos. La religión ha fomentado la sumisión, porque se ha basado principalmente en la culpa y el castigo. El catolicismo conserva aspectos ideológicos medievales, al presentar como normal la división social de funciones entre hombres y mujeres. De esta forma, la vida de las mujeres en Francia, durante el siglo decimonónico, estaba muy influenciada por la religión. Madame Grandet cree en el sentimiento de culpa y dice que le pedirá a Dios que la castigue solo a ella y no a su hija, por haberle mentido a su marido con respecto al dinero de Eugénie: "Je demanderai à Dieu de m'en punir seule"(225).

Además, existe un lazo muy fuerte que la une a su hija y, por esto, que la madre está dispuesta a asumir las consecuencias del enojo de su esposo. Ella comprende los sentimientos de su hija, a pesar de ser una mujer invisible, oprimida y aterrorizada por su marido:

Cette femme effacée, opprimée, terrorisée, cette «ilote» non seulement comprend l'amour de sa fille pour le jeune homme, mais est prête à accepter, et à en assumer personnellement les conséquences.

Para profundizar en el estudio de Madame Grandet, se indican a continuación diferentes aspectos de este personaje como la mujer, madre y esposa 
sumisas, dentro de la novela Eugénie Grandet, desde la perspectiva feminista.

\section{e. La mujer limitada al hogar}

Simone de Beauvoir refuta que se le niegue la instrucción y la cultura a la mujer, se le prohíbe desarrollar su individualidad. En Eugénie Grandet, Madame Grandet y su hija casi no salen y pasean solamente después de misa los domingos, debido a ciertos prejuicios católicos; según estos, se consideraba un pecado mortal en esa época que la mujer saliera a cualquier hora. Esto se puede ver cuando Charles les pregunta si ellas acostumbraban a pasear:

“- Vous ne vous promenez jamais?

- Quelques fois le dimanche après vêpres, quand il fait beau, dit madame Grandet, nous allons sur le pont, ou voir les foins quand on les fauche.

- Avez-vous un théâtre?

- Aller au spectacle, s'écria madame Grandet, voir des comédiens ! Mais, monsieur, ne savez vous pas que c'est un péché mortel?" (140).

Asimismo, esta feminista francesa afirma que la burguesía impone el sometimiento de la mujer, quien está confinada a la cocina y al hogar, se le vigila celosamente y queda encerrada en los ritos de un saber vivir que traba toda tentativa de independencia. Igualmente, destaca la opinión de Balzac quien afirma que: "la mujer casada es una esclava a quien hay que saber sentar sobre su trono". De acuerdo con esa declaración, Madame Grandet y su hija son calificadas por el narrador como dos criaturas sumergidas continuamente en la calma y la soledad, que llevan una vida monótona: "[...] ces deux créatures incessamment plongées dans le calme et la solitude [...]" (151) / "[...] leur existence monotone" (136).

La mayor parte de las actividades que realiza la madre las comparte con su hija. En la cita siguiente se puede observar la correspondencia en español con la utilización del gerundio "durmiendo", que da la impresión de la vida calmada e ingenua en la que vivían ambas mujeres: "Eugénie et sa mère, toujours ensemble, ensemble dans cette embrasure croisée, ensemble à l'église, et dormant ensemble dans le même air."

Madame Grandet y su hija no tienen oportunidad de desarrollar su propia personalidad, ya que los dos personajes están sometidos a las mismas actividades hogareñas:

Eugénie et sa mère sont montrées étroitement unies, elle partagent les mêmes activités laborieuses et subalternes -l'entretien du linge -, le même espace, les mêmes privations, la même vie monotone et paisible. [...] Les deux femmes paraissent également soumises.

Eugénie y su madre no tienen tampoco ninguna opción de instruirse en algo o de asistir a actos culturales como el teatro. Poulain de la Barre, feminista francés del siglo XVII, aboga por la igualdad de los sexos y opina que las mujeres tienen derecho a una educación equiparable a la de los hombres, sin ser sometida a prejuicios y a opiniones de los papeles establecidos socialmente. 


\section{f. La mujer le obedece al marido y es humillada}

En El Segundo Sexo, su autora expone la idea del matrimonio, impuesto tradicionalmente a la mujer como destino único que debe asumir según la sociedad. La mujer casada del siglo XIX debía ser obediente a su esposo y esto es exigido hasta 1942, de acuerdo con el código francés, que confería gran autoridad al hombre.

Madame Grandet considera a su esposo como su señor y su amo, lo que evidencia el servilismo y la obediencia que le tiene. También se puede decir que se muestra como una mujer tímida, con sentido de pertenencia al hombre, es decir, a su marido: "Et la pauvre femme, heureuse de pouvoir faire quelque chose pour un homme que son complesseur lui représentait son seigneur et son maître" (86).

Simone de Beauvoir estima que la mujer sumisa se ve obligada a soportar toda clase de humillaciones. Madame Grandet es una mujer que se siente humillada por la dependencia económica hacia su esposo y por el servilismo que le profesa, mientras que su carácter dulce le impide rebelarse o pedirle dinero o hacerle alguna observación sobre sus negocios, lo cual muestra de nuevo la sumisión total en que se encuentra:

[...] s'était toujours sentie si profondément humiliée d'une dépendance et d'un ilotisme contre lequel la douceur de son âme lui interdisait de se révolter, qu'elle n'avait jamais demandé un sou, ni fait une observation sur les actes que maître Cruchot lui présentait à signer. (85)
A pesar de la humillación en la que vive a causa de su marido, Madame Grandet es una mujer fiel y noble que domina su comportamiento aunque este la hiera: "Cette fierté sotte et secrète, cette noblesse d'âme constamment méconnue et blessée par Grandet, dominaient la conduite de cette femme" (85).

Simone de Beauvoir recalca una frase de Balzac: "la mujer es lo que su marido hace de ella". Evidentemente, Madame Grandet es una mujer acostumbrada a la dominación de su esposo, quien la ha hecho sumisa a lo largo de tantos años.

Por otro lado, se puede decir que la forma de vestir de Madame Grandet es un reflejo de su sumisión, ya que se viste con la misma ropa para no hacer gastar a su marido: "[...] elle s'était accoutumée à faire durer près d'une année" (85).

Poulain de la Barre considera "que las mujeres que habiendo sido educadas de una manera que las hace más sumisas y más tímidas que los hombres, se atan con mayor fuerza a la opinión y a la costumbre y les cuesta más abandonarlas". Un ejemplo es que Madame Grandet y Eugénie se habían acostumbrado a obedecer a Monsieur Grandet cuando este golpeaba la mesa con un martillo para recordarles su posición (de inferioridad) en la casa (163).

Simone de Beauvoir, por su parte, indica que para la mujer el amor es una total sumisión al servicio de su dueño, lo que hace que lo asuma de modo radical y aniquile su propia presencia. Tal es, sin duda, el caso de Madame Grandet, una esposa sumisa, tímida, obediente e invisible, pues su palabra como persona no cuenta. 


\section{g. La inferioridad de la mujer}

El reconocimiento de la opresión genérica, es decir, la ubicación de las mujeres en posición de dependencia, subordinación, inferioridad y exclusión, ha sido estudiado por los feministas, sobre todo a partir de la segunda mitad del siglo XX. Poulain de la Barre, desde el siglo XVII, expone la inferioridad de la mujer como el indicador más eficaz y determinante para analizar la sociedad. Algunas concepciones que se derivan de los estudios realizados por los y las feministas son las siguientes:

- Los hombres y las mujeres son sustancialmente diferentes, los hombres son superiores a las mujeres y los "hombres de verdad" lo son también a cualquier hombre que no se apegue a las normas aceptadas como ineludibles de la masculinidad dominante.

- La capacidad y el deseo de dominar a los demás y de triunfar en cualquier competencia son rasgos esenciales e ineludibles de la identidad de todos los hombres.

Esas ideas de dominación y superioridad masculinas se presentan en Eugénie Grandet. El comportamiento de Madame Grandet estaba dominado por completo por los deseos de su esposo: cada acción que ella realizaba era controlada por él, por ejemplo, cuando ella dormía, comía, bebía, y caminaba: "Quant à Madame Grandet, elle dormait, mangeait, buvait, marchait, suivant les désirs de son mari” (195).

Así, la madre es generalmente veterana y sobreviviente de un pasado de sumisión, transmite, que de manera silenciosa, pero efectiva, a su hija, lo que se llama la complicidad de las víctimas: "es muy importante que desde la infancia la niña sepa cuán inferior es al hombre y que la pretensión de las mujeres de ser iguales a los hombres debe ser totalmente destruida por la educación".

Madame Grandet y Eugénie son sumisas y obedientes a todo lo que Monsieur Grandet les dice; por ejemplo, ellas querían vestir de luto por la muerte del padre de Charles pero debían esperar la autorización del padre, con lo que demuestran ser incapaces de tomar una decisión sin el permiso del hombre de la casa:

- Maman, dit Eugénie, nous porterons le deuil de mon oncle.

- Ton père décidera de cela, répondit Madame Grandet. (151)

Por otro lado, en la descripción de Madame Grandet, se puede ver la imagen estereotipada de la mujer del siglo XIX en Francia: resignada, dulce, de apariencia angelical comparada a un insecto que es atormentado y se resigna a su situación de sumisión: "Une douceur angélique, une résignation d'insecte tourmenté..." (85).

La madre se presenta como ignorante y devota. En la referencia a continuación, Monsieur Grandet le habla a su sobrino de su esposa quien es incapaz de pensar por sí misma: "Votre tante est une dévote qui ne sait pas coudre deux idées" (106).

Geneviève Fraisse hace una crítica con respecto al saber femenino, el cual se creía desprovisto de razón, y de hacer uso público o privado de este. Monsieur Grandet trata a su esposa como una mujer 
ignorante cuando en una ocasión le dice que se vaya, porque no va a entender la conversación:

Il regarda sournoisement sa femme:

- Madame Grandet, ce que nous avons

à dire serait du latin pour vous... (165)

De acuerdo con lo expresado y citado, se puede ver la inferioridad de Madame Grandet ante su marido. Como apunta Geneviève Fraisse:

La mujer no ve en la sumisión, incluso en la más justa, más que los hierros de su servidumbre. [...] Entonces, se las arreglarán para que encuentre justa esa sumisión. Para lograrlo, producirán en ella el consentimiento, o más exactamente, le disfrazaran su inferioridad.

\section{h. El miedo y la sumisión}

En diversas ocasiones en la novela, el personaje de Madame Grandet muestra un profundo miedo hacia su esposo, como su hija que también le teme. Por ejemplo, esta teme que su marido envíe a su hija al monasterio (costumbre histórica) y dice que ella se encargará de hablarle, pues a ella no se la comerá. A pesar de esto, demuestra el miedo que siente por su esposo como si ella fuera la presa de un animal que se la puede llegar a comer: "- Non. Il t'enverrait à Noyers. Laisse-moi faire, il ne me mangera pas" (157).

También, siente miedo por la reacción de su marido cuando este se entere de que Eugénie ya no tiene el oro que él le había obsequiado y que debía enseñarle, según la tradición inventada por él, en el día de año nuevo debido a su terrible avaricia: "- Tu lui as tout donné, dit la mère épouvantée. Que diras-tu donc à ton père, au jour de l'an quand il voudra voir ton or" (213).

Madame Grandet y su hija sienten un temor tan grande del padre que pueden quedar en un estado de pánico durante la mitad de la mañana. El narrador utiliza la palabra espanto mortal: "Les yeux d'Eugénie devinrent fixes, et ces deux femmes demeurèrent dans un effroi ${ }^{5}$ mortel pendant la moitié de la matinée" (213).

Los personajes de la madre y la hija están durante la mayor parte del tiempo en una situación que les provocaba un temor evidente. Temen que Monsieur Grandet se entere del dinero que Eugénie ya no tenía pues lo había prestado a su primo Charles: "la terreur flagrante à laquelle la mère et la fille étaient en proie" (214).

Para ellas, la espera de la reacción del padre es peor que la muerte pública y deshonrosa, lo que les produce mucho miedo:

L'attente d'une mort ignominieuse et publique est moins horrible peutêtre pour un condamné que ne l'était pour madame Grandet et pour sa fille l'attente des événements qui devaient terminer ce déjeuner de famille. Plus gaiement parlait et mangeait le vieux vigneron, plus le cœur des ses deux femmes se serrait. (218)

Para Poulain de la Barre, ese miedo se traduce en la sumisión ciega que se rinde por costumbre. Esta actitud temerosa y pasiva confirma el sentimiento de debilidad e ignorancia, las amenazas y promesas que se hacen, las recompensas o castigos que se dan, y la experiencia del bien y del mal que se tiene hacia a aquel que ostenta el mando. Madame Grandet es comparada con 
un niño de la escuela que no aprendió sus lecciones y le teme al rostro irritado del profesor, en este caso su esposo: "La pauvre femme s'endormit comme l'écolier qui n'ayant pas appris ses leçons, craint de trouver à son réveil le visage irrité du maître" (157).

El miedo que Madame Grandet sufre ante su marido es evidente. Otro ejemplo es cuando Eugénie quiere poner el azúcar para su primo (el uso de este producto era restringido en la casa Grandet según las reglas del padre) y la madre manifiesta el temor que siente de su esposo por la reacción que podría tener. Ella repite varias veces la pregunta con respecto al padre:

- Mais que dira ton père?

- Et où prendras tu donc du sucre? Estu folle?

- Mais ton père. (105)

Las tres mujeres de la casa le temen a Monsieur Grandet. Sin embargo, Nanon, más que temor verdadero lo que siente hacia su patrón es un respeto por su condición de sirvienta. En una ocasión, el primo Charles se sorprende del miedo que experimentan a causa del padre, el cual es un avaro. Aunque no se hable en el momento de la escena, se percibe el miedo de las tres mujeres hacia Monsieur Grandet: "Il est impossible de se figurer l'intérêt profond que cette scène muette offrait à ces trois femmes" (143).

Asimismo, el narrador utiliza adjetivos como "mudas" y "perturbadas". También verbos como "palidecer", así como otros términos como "espanto", "miedo", "pánico", que ejemplifican el temor de las mujeres:
Les deux femmes étaient muettes. (213)

Troublées.' (213)

[...] voilà madame qui pâlit. (220)

Au moment où, par frayeur elle se roulait dans ses draps pour ne rien entendre...". (157)

Madame Grandet se dressa comme une biche effrayée. Ce fut une peur panique de laquelle Charles s'étonna, sans pouvoir se l'expliquer. (142)

Le père Grandet aperçut les morceaux de sucre, examina sa femme qui pâlit, et fit trois pas, il se pencha vers l'oreille de la pauvre vieille, et lui dit : où donc avez-vous pris tout ce sucre? (143)

Por otro lado, el narrador utiliza el adjetivo "bonhomme", término que en lengua francesa puede emplearse para designar a un hombre muy bonachón o muy cruel, lo cual se indica directamente en Eugénie Grandet: “[...] le mot bonhomme, déjà souvent employé pour designer Grandet, est décerné aux hommes les plus cruels comme aux plus bonasses, aussitôt qu'ils sont arrivés à un certain âge" (159). De esta manera, el lector puede interpretar el sentido de ese adjetivo usado para designar a Monsieur Grandet, según su comportamiento opresivo, que hacía sufrir a su hija y a su esposa.

\section{i. El sufrimiento en la mujer subor- dinada}

Al igual que su única hija, Madame Grandet sufre por la dominación de su 
esposo. Son varios los ejemplos que se pueden citar de la novela:

"Grandet ta colère me fera mourir dit la pauvre femme", "Je meurs" (220).

Madame Grandet llama señor a su marido y le pregunta si él le quitaría el derecho de ver a su hija pues este pretende encerrar a Eugénie en su habitación: "Voulez vous me priver de ma fille, monsieur?” (222).

Madame Grandet sufre una crisis de nervios y le dice a su esposo que de esa forma la va a matar: "Excitée pour la crise nerveuse [...]" "En vérité, Monsieur Grandet, si vous voulez me tuer, vous n'avez qu'à continuer ainsi" (224).

La madre sufre por el trato que recibe de su esposo: "L'effet du coup que m'a porté votre colère" (225).

La figura masculina del padre representa un hombre terrible que mantiene a su mujer en una subordinación constante. Monsieur Grandet dice querer a su esposa; sin embargo, la trata como a un objeto:

[...] le Grandet de Madame Grandet est un homme terrible, dont on peut craindre la violence, un tyran ${ }^{6}$ qu'il faut apaiser par une soumission constante et des prières à Dieu. Cet époux tout puissant n'a aucun égard pour cette femme qu'il dit pourtant aimer: elle est un meuble, fait pour durer.

Madame Grandet se enferma y sufre por causa de la crueldad de su esposo que le impide ver a su hija: "Si vous voulez rendre mes derniers moments moins amers..." (229).

Ella sabe que su marido se comporta mal y le pide a Dios que lo perdone: "Dieu vous pardonne" (229).

Madame Grandet considera a su esposo como un verdugo que tortura a
Eugénie, cuando habla de este con Monsieur Cruchot sobre el castigo de darle únicamente pan y agua a su hija de veintitrés años. Madame Grandet dice que eso es una tortura brutal, pero es incapaz de defender a su hija ante su esposo:

Mettre une fille de vingt-trois ans au pain et à l'eau...cela constitue des sévices tortionnaires; elle pourrait protester contre... (230)

Madame Grandet sufre a causa de su esposo quien domina su vida y la de su hija. El narrador dice que ella es devorada por la tristeza: "Madame Grandet, dévorée par le chagrin” (229).

Madame Grandet se presenta como un ser débil y que podría, no obstante, desobedecer la autoridad de su marido, pero no se atreve a hacerlo. Como indica Geneviève Fraisse, un ser débil, aparentemente destinado a la sumisión, es un ser capaz por su misma naturaleza, de "rebelarse contra la dominación".

La madre está, al igual que Eugénie, en una especie de penumbra, sus miedos y actitudes no le permiten hacer uso pleno de su persona. Se dice que la causa de su muerte fueron los conflictos entre su esposo y su hija: "Elle vit dans l'ombre de son mari, ne trouvant de bonheur que dans la religion et l'amour maternel. Cette femme sacrifiée meurt en 1822, minée par le conflit entre Grandet et sa fille".

Se dice que Madame Grandet es el personaje más sacrificado de la novela Eugénie Grandet, ya que es una mujer desdichada, sumisa bajo la tiranía de $\mathrm{su}$ esposo y literalmente inexistente desde el inicio del relato.

La sumisión a la que obedecen la madre y la hija puede ser considerada impuesta por las tradiciones: la esposa 
debe obedecer al marido y por el parentesco: Eugénie no tiene otra opción, ya que ella no escogió ser hija de Monsieur Grandet.

\section{Notas}

1. Ciega y baja adhesión a la autoridad de una persona.

2. Esclava, persona que sin ser esclava está sometida a la servidumbre.

3. Reid, Martine, Eugénie Grandet in Honoré de Balzac, París, Librairie Générale Française, 1996. En adelante, se indicará el número de página del mismo libro.

4. Gemir: expresar dolor con sonido quejumbroso.

5. Espanto. Grande frayeur.

6. La negrita es original del texto en esta cita.

7. Persona que torture a otra para hacerla confesar por medio del sadismo. Personne qui torture quelqu'un pour lui arracher des aveux par sadisme.

\section{Bibliografía}

BALZAC, Honoré de. Euvres Complètes illustrées d'Honoré de Balzac. Tome premier, Tome deuxième, Tome troisième. París: Guy le Prat, 1960.

BLOCH-DANO, Evelyne. Eugénie Grandet Honoré de Balzac. París: Éditions Nathan, 1995.

BORLOZ SOTO, Virginia. Madame Bovary soy yo. San José: Editorial de la UNED, 2001.

BRAHIMI-CHAPUIS, Denise y Lucile Kuentzmann. Images de la Femme. Poitiers: Éditions Delagrave, 1976.

CALVO, Yadira. A la Mujer por la Palabra. Heredia: Editorial de la Universidad Nacional, 1990.
- Literatura, mujer y sexismo. San José: Editorial Costa Rica, 1991.

CHELIN, Jean. Dossier Les Catholiques. Historia Thématique, $\mathrm{N}^{\circ}$ 91, setiembre - octubre, 2004.

COUTY, Daniel. Histoire de la Littérature Française. Manche Court: Éditions Larousse, 2000.

DE LA BARRE, Poulain. De la educación de las damas para la formación del espíritu en las ciencias y en las costumbres. Madrid: Ediciones Cátedra, 1993.

DE BEAUVOIR, Simone. El Segundo Sexo. 2 vols. Pablo Palant (trad.). Buenos Aires: Ediciones Siglo Veinte, 1972.

DESYEUX SANDOR, Monique y Martine Dal Zotto. Anthologie de la littérature française XIX e siècle. París: Librairie Générale Française, 1995.

Dictionnaire Larousse de Poche. París: Éditions Larousse, 1994.

FRAGONARD, Marie-Madeleine. Précis d'histoire de la littérature française. París: Éditions Didier, 1981.

FRAISSE, Geneviève. Musa de la razón: La democracia excluyente y la diferencia de los sexos. Alicia H. Puleo (trad.). Madrid: Ediciones Cátedra, 1991.

GONZÁLEZ SUÁREZ, Mirta. El sexismo en la educación. San José: Editorial de la Universidad de Costa Rica, 1992.

Groupe d'Etudes Balzaciennes. L'Année balzacienne 1992, Balzac et l'Europe. París: Presses Universitaires de France, 1992.

HAMON, Philippe y Denis Roger Vasselin. Le Robert des grands écrivains de langue française. Manche Court: Dictionnaires Le Robert, 2000.

L'HERMITE LECLERQ, Paulette. Dossier Femmes du Moyen Âge. Historia Thématique, N$^{\circ}$ 688. Abril, 2004. 
KUNSTLER, Charles. La vie quotidienne sous Louis XVI. París: Hachette, 1950.

LAGARDE, André y Laurent Michard. Textes et Littérature: Le Moyen Âge. Collection Littéraire Lagarde \& Michard. París: Bordas, 1970.

Textes et Littérature: "Le XVII Siècle" Collection Littéraire Lagarde \& Michard. París: Bordas, 1970.

Textes et Littérature: "Le XVIII" Siècle" Collection Littéraire Lagarde \& Michard. París: Bordas, 1970.

Textes et Littérature: "Le XIX Siècle" Collection Littéraire Lagarde \& Michard. París: Bordas, 1970.

MATHIEX, Jean. Histoire de France. París: Hachette, 1996.

MOZET, Nicole. La ville de province dans l'œuvre de Balzac. París: Société d'édition d'enseignement supérieur, 1982.

MONGREDIEN, Georges. La vie quotidienne sous Louis XIV. París: Hachette, 1948.
PERNOUD, Régine. Lumière du Moyen Âge. París: Editions Bernard Grasset, 1981.

POMAREDE, Valérie. Dossier Femmes du Moyen Âge. Historia Thématique, No 688. Abril, 2004.

REID, Martine, Eugénie Grandet in Honoré de Balzac, París: Librairie Générale Française, 1996.

TABORGA, Carolina y Diana Rrenn. Perspectiva de género Glosario de términos. Roma: IPS, 1997.

VERDON, Jean. Dossier Les Catholiques. Historia Thématique, No 91, setiembre- octubre, 2004.

VERDON Laure. Dossier Femmes du Moyen Âge. Historia Thématique, № 688, abril, 2004.

WILLIAMS Edwin B. Williams Diccionario del Idioma Español. New York: Washington Square Press, 1963. 
